Die Frau im Dialog 
Ergebnisse der Frauenforschung

Band 21

Herausgegeben im Auftrag des Präsidenten der Freien Universität Berlin von

Prof. Anke Bennholdt-Thomsen, Germanistik

Prof. Ingeborg Falck, Medizin

Prof. Marion Klewitz, Geschichtsdidaktik

Prof. Jutta Limbach, Jura

Prof. Renate Rott, Soziologie

Dr. Hanna Beate Schöpp-Schilling, Aspen Institut

Ulla Bock (Zentraleinrichtung zur Förderung von Frauenstudien und Frauenforschung)

Prof. Hans Oswald, Pädagogik

Koordination: Anita Runge 


\section{DIE FRAU IM DIALOG}

Studien zu Theorie und Geschichte des Briefes

Herausgegeben von Anita Runge und Lieselotte Steinbrügge

J. B. Metzlersche Verlagsbuchhandlung Stuttgart 
CIP-Titelaufnahme der Deutschen Bibliothek

Die Frau im Dialog : Studien zu Theorie und Geschichte des Briefes / hrsg. von Anita Runge und Lieselotte Steinbrügge. - Stuttgart: Metzler, 1991

ISBN 978-3-476-00759-9

NE: Runge, Anita [Hrsg.]

ISBN 978-3-476-00759-9

ISBN 978-3-476-03362-8 (eBook)

DOI 10.1007/978-3-476-03362-8

Dieses Werk einschließlich aller seiner Teile ist urheberrechtlich geschützt. Jede Verwertung außerhalb der engen Grenzen des Urheberrechtsgesetzes ist ohne Zustimmung des Verlages unzulässig und strafbar. Das gilt insbesondere für Vervielfältigungen, Übersetzungen, Mikroverfilmungen und die Einspeicherung und Verarbeitung in elektronischen Systemen.

(C) 1991 Springer-Verlag GmbH Deutschland Ursprünglich erschienen bei J. B. Metzlersche Verlagsbuchhandlung und Carl Ernst Poeschel Verlag GmbH in Stuttgart 1991 


\section{Inhaltsverzeichnis}

Einleitung

I.

Regina Nörtemann

Die "Begeisterung eines Poeten« in den Briefen eines

Frauenzimmers. Zur Korrespondenz der Caroline

Christiane Lucius mit Christian Fürchtegott Gellert

Herta Schwarz

Poesie und Poesiekritik im Briefwechsel zwischen

Clemens Brentano und Sophie Mereau

II.

Elfi Bettinger

Women of letters. Die politische Briefliteratur von Aphra

Behn, Delarivier Manley und Eliza Haywood

Lieselotte Steinbrügge

Kritische Briefe zur Kultur der Aufklärung.

Madame Riccobonis Lettres de Milord Rivers

Anita Runge

Die Dramatik weiblicher Selbstverständigung in den

Briefromanen Caroline Auguste Fischers

III.

Beatrix Borchard

Clara Schumann: Die Witwe als Herausgeberin

115

Irmela von der Lühe

Mythos zu Lebzeiten? Selbst- und Fremdbilder in den Briefen

und Briefromanen Franziska zu Reventlows 
Angelika Ebrecht

Rettendes Herz und Puppenseele. Zur Psychologie der

Fernliebe in Rilkes Briefwechsel mit Magda von Hattingberg

IV.

\section{Ulrike Scholvin}

"...diese Entfernung wird dir mehr geben als oft meine

Gegenwart«. Zur Poetologie von Goethes Italienischer Reise

Anke Bennholdt-Thomsen

Zur Geschichtlichkeit des Liebesbriefs. Eine dissonante

Dokumentation aus dem Jahre 1930

Gudrun Kohn-Waechter

Das »Problem der Post« in Malina von Ingeborg Bachmann und Martin Heideggers Der Satz vom Grund 